\title{
Crédito Rural e Agricultura Familiar no Brasil: uma avaliação do Programa Nacional de Fortalecimento da Agricultura Familiar
}

\author{
Jair Andrade Araújo \\ Universidade Federal do Ceará - Fortaleza - CE - Brasil \\ ORCID: https://orcid.org/0000-0001-6297-9558 \\ Matheus Oliveira de Alencar \\ Universidade Federal do Rio Grande do Sul - Porto Alegre - RS - Brasil \\ ORCID: https://orcid.org/0000-0002-9594-6354 \\ José Eustáquio Ribeiro Vieira Filho \\ Instituto de Pesquisa Econômica Aplicada - Brasília - DF - Brasil \\ ORCID: https://orcid.org/0000-0002-2682-1240
}

\begin{abstract}
Resumo
Este estudo tem como objetivo principal apresentar e discutir os impactos do Programa Nacional de Fortalecimento da Agricultura Familiar (Pronaf) sobre a renda e a produtividade na agricultura familiar brasileira. Para alcançar o objetivo proposto, foram utilizados dados da Pesquisa Nacional por Amostra de Domicílios (PNAD) do ano de 2014 e empregou-se como método de análise o Propensity Score Matching (PSM). Observou-se que o programa apresenta efeito médio positivo de $10,9 \%$ sobre a renda dos seus beneficiários em relação aos não beneficiários. Quanto ao efeito do Pronaf sobre a produtividade agropecuária, os beneficiários do Pronaf apresentam em média uma produtividade 15,2\% maior em comparação aos não beneficiários.
\end{abstract}

Palavras-chave: Agricultura familiar. Crédito rural. Pronaf. Renda. Produtividade agropecuária.

Rural Credit and Family Farming in Brazil: An Evaluation of the National Program for Strengthening Family Farming

Abstract

This study aims to present the impacts of the National Program for Strengthening Family Farming (Pronaf) on income and productivity in Brazilian family farming. To achieve the proposed objective, data from the National Household Sample Survey (PNAD) of 2014 were 
used and was used as the analysis method the Propensity Score Matching (PSM). It was observed that the program has a positive average effect of $10.9 \%$ on the income of its beneficiaries compared to non-beneficiaries. Regarding the effect of Pronaf on agricultural productivity, Pronaf beneficiaries have an average productivity $15.2 \%$ higher than nonbeneficiaries.

Keywords: Family farming. Rural credit. Pronaf. Income. Agricultural Productivity.

\section{Crédito Rural y Agricultura Familiar en Brasil: una evaluación del Programa Nacional para Fortalecemiento de la Agricultura Familiar}

\section{Resumen}

El objetivo de este estudio es presentar los impactos del Programa Nacional para Fortalecer la Agricultura Familiar (Pronaf) sobre los ingresos y la productividad en la agricultura familiar brasileña. Para lograr el objetivo propuesto, se utilizaron los datos de la Encuesta Nacional de Muestra de Hogares (PNAD) de 2014 y como método de análisis el Propensity Score Matching (PSM). Se observó que el programa tiene un efecto promedio positivo del $10.9 \%$ sobre los ingresos de sus beneficiarios en comparación con los no beneficiarios. Con respecto al efecto de Pronaf en la productividad agrícola, los beneficiarios de Pronaf tienen una productividad promedio $15.2 \%$ más alta que los no beneficiarios.

Palabras clave: Agricultura familiar. Crédito rural. Pronaf. Ingresos. Productividad Agrícola.

\section{Introdução}

O setor agropecuário economia é de grande relevância para a economia brasileira, sendo responsável por aproximadamente $20 \%$ do valor do produto interno bruto (PIB) do Brasil. O financiamento das atividades agropecuárias desempenha um papel essencial para o desenvolvimento do setor, pois possibilita, entre outros benefícios, ganhos de produtividade, principalmente em virtude dos avanços tecnológicos. Nesse contexto, o crédito rural tem sido a principal ferramenta de política agrícola para impulsionar a produtividade e o desenvolvimento do setor agropecuário brasileiro (LOPES et al. 2016).

No bojo do fomento ao setor agropecuário, o Plano Safra, instituído pelo governo brasileiro, reúne um conjunto de políticas públicas direcionadas ao setor agropecuário, tais como serviços de assistência técnica e extensão rural, crédito, seguro de produção e garantia de preço, comercialização e organização econômica das famílias residentes no campo, entre outras medidas. Esse plano é aperfeiçoado anualmente de forma a interagir melhor com o agricultor e suas necessidades, criando melhores oportunidades para o desenvolvimento rural brasileiro (BRASIL, 2017).

Há diversos mecanismos de políticas no Plano Safra 2017/2018, como os projetos voltados para a armazenagem, com o Programa para Construção e Ampliação de Armazéns (PCA), e a inovação tecnológica na agricultura, com o Programa de Incentivo à Inovação Tecnológica na Produção Agropecuária (Inovagro), cuja taxa de juros é de $6,5 \%$ ao ano (a.a.). Em relação ao crédito, 
destinou-se ao custeio e à comercialização o montante de $\mathrm{R} \$ 150,25$ bilhões, sendo $\mathrm{R} \$ 116,25$ bilhões com juros controlados (taxas fixadas pelo governo) e $\mathrm{R} \$ 34$ bilhões com juros livres (livre negociação entre a instituição financeira e o produtor) (BRASIL, 2017).

Entre as políticas de crédito voltadas para a produção de menor escala, destaca-se o Programa Nacional de Fortalecimento da Agricultura Familiar (Pronaf), criado em 1996 como instrumento de política pública para fomentar o desenvolvimento da agricultura familiar. De acordo com Teles (2007) e Bittencourt (2003), antes do surgimento do Pronaf, os agricultores familiares brasileiros tinham acesso limitado ao crédito rural por conta do desinteresse de bancos ou de instituições financeiras em financiar a população agrícola de baixa renda. Dessa forma, o Pronaf foi desenvolvido no contexto de suprir a redução da atuação estatal no crédito rural dos anos 80 e início dos 90.

Essa política financia projetos individuais ou coletivos que buscam gerar renda aos agricultores familiares e assentados da reforma agrária, e destina-se a estimular a geração de renda e melhorar o uso da mão de obra familiar, por meio do financiamento de atividades e serviços rurais agropecuários e não agropecuários desenvolvidos em estabelecimento rural ou em áreas comunitárias próximas. Seus beneficiários são agricultores e produtores rurais que compõem as unidades familiares de produção rural (BRASIL, 2017).

Nesse contexto, este estudo tem como objetivo principal apresentar e discutir os impactos do Programa Nacional de Fortalecimento da Agricultura Familiar (Pronaf) sobre a renda e a produtividade na agricultura familiar brasileira. Pretende-se também apresentar um panorama acerca da distribuição do número de contratos e do volume de recursos entre as grandes regiões e estados brasileiros.

Para alcançar o objetivo proposto, foram utilizados dados da Pesquisa Nacional por Amostra de Domicílio do ano de 2014 (PNAD, 2014) e do Anuário Estatístico do Crédito Rural do Banco Central do Brasil (BCB, 2018). Para a apresentação da distribuição do número de contratos e do volume de recursos entre as grandes regiões e estados brasileiros, realizou-se estatística descritiva referente aos anos de 2013 a 2017. Já para mensurar os impactos do Pronaf sobre a renda e a produtividade na agricultura familiar brasileira, foi utilizado o método Propensity Score Matching (PSM).

Além de contribuir para a discussão na literatura sobre a temática, a relevância deste estudo consiste no fato de fornecer informações importantes em relação aos efeitos dessa importante política de crédito, o que dá suporte para os agentes públicos na tomada de decisões quanto a ampliação ou possíveis aperfeiçoamentos na mesma.

Além desta introdução, este artigo está dividido em mais quatro seções. A seção 2 faz a revisão da literatura, descrevendo o crédito rural e o Pronaf. A seção 3 expõe a metodologia e a base de dados utilizadas, bem como a estratégia empírica adotada. A seção 4 apresenta a discussão e a análise dos resultados. Por fim, seguem-se as considerações finais.

\section{Revisão de literatura}


A literatura sobre o Pronaf é muito extensa. Além disso, é composta por diversas abordagens de análise do programa. É possível, por exemplo, citar trabalhos que se propuseram a construir uma síntese do programa e seus resultados, como, por exemplo, Schneider et al. (2004) e Mattei (2007).

Outros estudos procuraram mensurar os impactos diretos do Pronaf nas mais diversas escalas geográficas. A nível nacional, Guanziroli (2007) analisou a eficiência do programa na geração de renda, Araujo e Vieira Filho (2018) mensuraram os efeitos dos choques de crédito ofertado pelo Pronaf, através da quantidade e do valor agregado dos contratos da agricultura e pecuária, sobre a área plantada, o valor bruto da produção agrícola e a pecuária e produtividade da terra, e Marioni et al. (2016) avaliaram o impacto do Pronaf no PIB da economia brasileira e nos PIBs setoriais (PIB de serviços, agropecuário e industrial).

Quanto as pesquisa realizada para regiões específicas, destacam-se Castro et al. (2014) que analisaram os impactos regionais do Pronaf, para cada uma das cinco regiões do país, Kageyama (2003) que comparou características econômicas e sociais dos produtores agrícolas familiares que receberam com os que não receberam crédito do Pronaf, Magalhães et al. (2006) que avaliaram a experiência do Pronaf entre os agricultores do estado de Pernambuco, Tales (2007) que avaliou o impacto do PRONAF na produção agrícola dos municípios do estado do Ceará, Silva e Alves Filho (2009) que buscaram mensurar os impactos econômicos do Pronaf na economia local do Médio Jequitinhonha, em Minas Gerais, Rodrigues (2019) que analisou os efeitos do Pronaf nos Produtos Internos Brutos total e setorial da mesorregião da Zona da Mata de Minas Gerais entre 2001 e 2012, Antunes et al. (2013) que avaliaram o impacto do PRONAF na economia de 60 municípios paranaenses, e Gazolla e Schneider (2013) que avaliaram a linha de crédito de investimento e custeio do Pronaf para a agricultura familiar no Rio Grande do Sul. Além destes, existem diversos outros estudos que se dedicam a avaliar a repercussão regional do Pronaf.

Pode-se citam também, estudos que se dedicam a investigar Pronaf como ferramenta de promoção do desenvolvimento rural, tais como Carmo e Clemente (2018) que analisaram os efeitos do Pronaf sobre condições de vida dos assentados nos assentamentos rurais dos municípios paulistas de Caiuá e Teodoro Sampaio, com uma amostra de 1.407 famílias e Silva et al. (2017) que observaram a configuração espacial na distribuição do crédito do Pronaf entre regiões geográficas brasileiras, por modalidades de investimentos e custeios e por faixa de valor, traçando um paralelo com o desenvolvimento rural.

No que se refere ao presente estudo, a contribuição frente aos diversos trabalhos existentes sobre o tema é relevante, primeiramente, pelo método de análise empregado, que é capaz de capturar o efeito médio direto da política sobre as variáveis de interesse, neste caso, o nível de renda e produtividade do pequeno produtor rural. Além disso, este estudo faz uso de uma base de dados bem consolidada, com informações recentes e pouco exploradas para analisar questões dentro da temática abordada por esta pesquisa, além de abordar a questão a nível nacional. Sendo assim, dado que não se observou estudos anteriores que considerassem todos estes pontos, este trabalho traz importantes contribuições para a literatura, principalmente, por fornecer novas evidências no que diz respeito 
a efetividade do programa diretamente sobre a renda e produtividade dos produtores rurais beneficiados.

\subsection{Crédito agrícola no Brasil e o Pronaf}

No Brasil, a oferta de crédito para o setor agropecuário se consolidou com a instituição do Sistema Nacional de Crédito Rural (SNCR), em 1965. O SNCR foi estabelecido com a finalidade de fornecer crédito rural de baixo custo para financiar a produção, a compra de maquinário, e os custos de operação e de comercialização dos produtos do setor agropecuário, caracterizando-se como o principal incentivo para a modernização da agricultura brasileira. Suas políticas de concessão de crédito rural permitiram que muitos produtores tivessem a oportunidade de utilizar recursos mais modernos na agricultura (SANTOS; BRAGA, 2013).

Com a criação do SNCR, foram estabelecidos três objetivos principais, válidos até hoje. $\mathrm{O}$ primeiro consiste em garantir o acesso ao crédito com taxas de juros abaixo das praticadas no mercado. O segundo diz respeito à exigência legal junto aos bancos para que destinem parcela de seus depósitos à vista a linhas de crédito rural. O terceiro objetivo é incentivar os pequenos produtores rurais com taxas de juros ainda mais baratas, por meio de linhas de crédito direcionadas (LOPES et al. 2016).

No entanto, segundo Melo et al. (2013), desde a criação do SNCR, o crédito rural vem passando por fortes modificações, afetado por fatores como: altos índices de inflação, oscilações nos preços dos insumos do setor, interferências políticas, restrição de recursos financeiros, entre outros. As principais modificações referem-se ao valor da taxa de juros real cobrada e a participação dos bancos públicos no fornecimento de crédito rural.

Até 1985 , o sistema de crédito rural operou com juros reais negativos, o que gerou uma forte demanda de crédito para fins especulativos, não necessariamente para o financiamento de atividades agropecuárias. Só a partir de 1992, a concessão de crédito rural começou a trabalhar com taxas de juros reais positivas. Em 2008, a participação dos bancos públicos no fornecimento de crédito rural era $55 \%$ do volume disponibilizado. Esse percentual, consideravelmente menor que os $80 \%$ no período 1994-1995, no início do Plano Real, caracteriza um distanciamento do governo do financiamento direto no setor primário (MELO et al. 2013).

Apesar da diminuição da participação dos bancos públicos no fornecimento de recursos para o crédito rural, o volume total de crédito para financiamento de atividades do setor agropecuário demonstra trajetória crescente $(B C B, 2018)$.

A chamada Lei da Agricultura Familiar (Lei $n^{\circ} 11.326$, de 24 de julho de 2006) estabelece a formulação de uma política nacional de agricultura familiar e de empreendimentos familiares rurais. Segundo esse dispositivo, serão considerados estabelecimentos familiares os que se enquadrarem nos seguintes requisitos: i) ser agricultor ou empreendedor que pratica atividade no meio rural; ii) não deter, a qualquer título, área maior do que quatro módulos fiscais;1 iii) utilizar

2. O tamanho do módulo fiscal varia entre 5 e 110 ha, dependendo da sua localidade (Landau et al. (2015). 
predominantemente mão-de-obra da própria família nas atividades econômicas do seu estabelecimento ou empreendimento; iv) ter percentual mínimo da renda familiar originada de atividades econômicas do seu estabelecimento ou empreendimento, na forma definida pelo Poder Executivo; e v) dirigir seu estabelecimento ou empreendimento com sua família (BRASIL, 2006).

Por critérios de exclusão, os agricultores e empreendedores rurais que não atendem simultaneamente a todos esses requisitos serão classificados como não familiares, ou do tipo patronal. Em outros termos, serão os estabelecimentos com mais de quatro módulos fiscais com apenas mão de obra assalariadas ou dirigidos por administradores (BRASIL, 2017). Logo, tanto Kageyama et al. (2013) como Aquino et al. (2018) concluíram que os estabelecimentos agrícolas foram denominados não apenas por seu tamanho/área, mas principalmente pelo tipo de relação social na produção, se são por familiares ou pela interação patrãoempregado.

A partir das informações extraídas do censo agropecuário de 2006 (IBGE, 2009), dos 5.175.636 estabelecimentos agropecuários no Brasil, o segmento familiar representava $84,36 \%$ - ou seja, 4.366 .267 famílias. Já o não familiar, ou patronal, registou apenas 809.369 estabelecimentos, representando somente $15,64 \%$ do total. Por outro lado, no que se refere à distribuição de área total de terra por cada tipo de produção, os papéis se invertem: os produtores patronais concentram $76 \%$ do total da área rural de produção no Brasil, atingindo 253.577.343 ha. Por sua vez, de forma menos representativa, os agricultores familiares detinham apenas $24 \%$ ou 80.102.694 ha, ocupando uma área média por volta de vinte vezes menor do que o setor patronal.

Diante do exposto, o principal objetivo do Pronaf é o financiamento do crédito rural para as operações de custeio e investimento de projetos coletivos ou individuais a fim de gerar renda para agricultores familiares e assentados da reforma agrária, e, consequentemente, aumentar a produtividade da agricultura. Araujo e Vieira Filho (2018) consideram o Pronaf não apenas um programa destinado à oferta de crédito, mas também como uma ação efetiva para um planejamento territorial local, que acarretaria no processo de desenvolvimento. Guanziroli (2007) destacou em sua pesquisa que o Pronaf surgiu para abrandar os problemas principais enfrentados pelos agricultores familiares, principalmente no que se referia a escassez de crédito, como também aos altos custos da produção.

De maneira mais formal, a Resolução no 4.107, de 28 de junho de 2012, afirma que o objetivo do Pronaf é estimular a geração de renda e melhorar o uso da mãode-obra familiar, a partir do financiamento de atividades e serviços rurais agropecuários e não agropecuários desenvolvidos em estabelecimentos rurais ou nas áreas comunitárias mais próximas (BRASIL, 2017). Para Magalhães et al. (2006), o Pronaf é uma das políticas públicas mais efetivas na área agrícola e social no Brasil.

Além do forte investimento, que foi sendo ampliado no decorrer do tempo, Castro et al. (2014) destacam que as taxas de juros subsidiadas também são consideradas as principais características do programa. O intuito do Pronaf é, não apenas permitir o acesso de pequenos produtores à realização de investimento, como também reduzir a pobreza e as desigualdades sociais entre os agricultores familiares brasileiros. 
Para Silva et al. (2017), o surgimento do Pronaf veio como uma boa alternativa de crédito para os agricultores, pois o processo facilitado para obter financiamento, os baixos juros e os maiores prazos do mercado são considerados características determinantes que estimulam os produtores a aderir ao programa. De acordo com esses autores, no entanto, o programa passou a ter maior relevância e robustez apenas no início dos anos 2000, quando passou a ser observado um maior estímulo na produção rural.

Do mesmo modo, Vieira Filho e Silveira (2016) afirmam que o Pronaf, por meio principalmente de ações relacionadas ao suporte de assistência técnica, busca garantir o desenvolvimento da infraestrutura, em especial dos agricultores de pequeno porte. A intenção é aumentar sua capacidade produtiva, procurando garantir não só o acesso como também a sua absorção tecnológica.

A partir do momento que decidem aderir ao financiamento do crédito rural disponibilizado por meio do Pronaf, as famílias devem pedir informações aos sindicatos que possam lhes orientar. De forma mais direta, podem entrar em contato com a Empresa de Assistência Técnica e Extensão Rural (Emater) e obter a Declaração de Aptidão (DAP) junto ao Pronaf. Tendo tal informação como base, os agricultores rurais que se enquadram e demandam o crédito serão classificados de acordo com a renda advinda da atividade rural, a quantidade de empregos gerados no âmbito rural de produção, a renda bruta anual e o tamanho da propriedade (BRASIL, 2017).

Os beneficiados são enquadrados nas seguintes categorias: grupos $A, A / C, B$, agricultores familiares e outros. De acordo com a Resolução no 4.107, de 28 de junho de 2012, classificam-se no grupo A os assentados pelo Plano Nacional de Reforma Agrária (PNRA) ou beneficiários do Programa Nacional de Crédito Fundiário (PNCF). Do mesmo modo, no grupo B, segundo a Resolução no 4.253, de 16 de julho de 2013, são beneficiários os produtores cuja renda familiar anual não seja superior a R\$ 20 mil, e que não contem com trabalhadores assalariados permanentes. Por fim, a Resolução no 4.107 denomina o grupo A/C, composto pelos assentados do PNRA ou dos beneficiários do PNCF que tenham contratado a primeira operação no grupo A mas que não tenham contratado financiamento de custeio, exceto no próprio grupo A/C (BRASIL, 2017).

No grupo de agricultores familiares, delimitam-se os posseiros, os proprietários, arrendatários, parceiros, comodatários, concessionários do PNRA ou permissionários de áreas públicas que cultivem em uma parcela da terra e que obtenham, no mínimo, $50 \%$ da renda familiar bruta proveniente da exploração agropecuária. No que tange ao grupo composto pelos demais beneficiários, estão incluídos os pescadores artesanais com fins comerciais, os silvicultores, os agricultores que cultivam organismos que tenham água, os integrantes de comunidades quilombolas, os extrativistas, as comunidades tradicionais e os povos indígenas (BRASIL, 2017).

Serão apresentadas a partir de agora as evidências disponibilizadas pelo Anuário Estatístico do Crédito Rural do Banco Central do Brasil $(B C B, 2018)$ a respeito do comportamento do crédito rural disponibilizado pelo Pronaf nos últimos anos de sua existência. A Tabela 1 apresenta a participação dos contratos de financiamento oriundos do Pronaf no total de contratos de crédito rural por regiões brasileiras, no período entre 2013 e 2017. 
Crédito Rural e Agricultura Familiar no Brasil: uma avaliação do Programa Nacional de Fortalecimento da Agricultura Familiar

Tabela 1. Participação percentual dos contratos de financiamento do Pronaf no total de contratos de crédito rural por regiões e estados brasileiros (2013-2017)

\begin{tabular}{|c|c|c|c|c|c|}
\hline \multirow{2}{*}{ Região } & \multicolumn{5}{|c|}{ Ano } \\
\hline & 2013 & 2014 & 2015 & 2016 & 2017 \\
\hline SUL & 61,77 & 60,92 & 63,05 & 64,01 & 62,96 \\
\hline Paraná & 56,97 & 56,72 & 59,27 & 59,68 & 58,02 \\
\hline Rio Grande do Sul & 62,71 & 60,87 & 63,29 & 64,82 & 63,78 \\
\hline Santa Catarina & 65,78 & 67,12 & 68,44 & 68,79 & 68,52 \\
\hline SUDESTE & 56,30 & 58,29 & 57,62 & 58,47 & 51,42 \\
\hline Minas Gerais & 62,74 & 64,90 & 64,75 & 66,24 & 55,41 \\
\hline São Paulo & 32,13 & 34,39 & 33,81 & 29,79 & 167,46 \\
\hline Espírito Santo & 60,94 & 63,46 & 55,93 & 64,30 & 66,39 \\
\hline Rio de Janeiro & 72,27 & 75,84 & 80,17 & 78,20 & 74,47 \\
\hline CENTRO-OESTE & 30,87 & 33,71 & 33,05 & 31,38 & 27,92 \\
\hline Mato Grosso & 39,55 & 45,24 & 44,52 & 43,76 & 39,81 \\
\hline Goiás & 28,67 & 29,59 & 28,53 & 27,08 & 24,16 \\
\hline Mato Grosso do Sul & 23,51 & 25,30 & 25,48 & 22,35 & 19,13 \\
\hline Distrito Federal & 28,30 & 34,70 & 26,36 & 24,18 & 18,16 \\
\hline NORDESTE & 94,39 & 94,29 & 95,62 & 95,92 & 92,29 \\
\hline Bahia & 91,25 & 91,23 & 93,52 & 94,11 & 89,16 \\
\hline Maranhão & 91,36 & 91,72 & 92,34 & 92,96 & 85,52 \\
\hline Piauí & 96,88 & 96,72 & 97,60 & 97,56 & 94,91 \\
\hline Ceará & 96,08 & 95,70 & 96,67 & 97,02 & 94,99 \\
\hline Pernambuco & 96,48 & 96,81 & 97,85 & 97,61 & 95,09 \\
\hline Alagoas & 97,17 & 96,55 & 97,61 & 97,26 & 94,78 \\
\hline Paraíba & 95,86 & 96,35 & 97,23 & 97,69 & 96,43 \\
\hline Sergipe & 94,43 & 93,08 & 94,09 & 93,68 & 89,13 \\
\hline Rio Grande do Norte & 96,03 & 96,00 & 97,03 & 97,86 & 96,64 \\
\hline NORTE & 77,78 & 77,48 & 74,78 & 72,85 & 67,13 \\
\hline Tocantins & 51,43 & 51,87 & 52,42 & 47,65 & 32,62 \\
\hline Pará & 83,79 & 83,07 & 82,71 & 78,16 & 72,88 \\
\hline Rondônia & 77,48 & 82,59 & 76,87 & 78,98 & 75,52 \\
\hline Acre & 91,45 & 93,66 & 90,55 & 87,69 & 88,32 \\
\hline Amazonas & 97,71 & 79,16 & 82,43 & 89,34 & 87,35 \\
\hline Roraima & 83,47 & 81,49 & 85,17 & 88,19 & 80,55 \\
\hline Amapá & 95,62 & 97,36 & 94,48 & 93,40 & 87,32 \\
\hline BRASIL & 70,89 & 70,35 & 72,84 & 73,69 & 65,27 \\
\hline
\end{tabular}

Fonte: Elaboração própria com base em dados do Anuário Estatístico do Crédito Rural do Banco Central do Brasil. Disponível em: https://www.bcb.gov.br/estabilidadefinanceira/micrrural.

Como pode ser observado (Tabela 1), os contratos firmados pelo Pronaf no Brasil, nesse período, representaram por volta de $70 \%$ do número total de contratos de crédito rural. Em 2017, essa representatividade foi bem menor que a média do período, com concentração de $65 \%$ dos contratos de crédito rural (em 2016 observou-se a maior participação do Pronaf, com $73,7 \%$ dos contratos). Sendo assim, 
no que se refere à agricultura familiar, ao longo dos últimos anos tornou-se evidente um comportamento de certa forma estável do programa na distribuição de seus financiamentos.

Em relação ao seu peso no número de contratos de crédito rural nas regiões e nos seus respectivos estados, nota-se uma intensa participação do Pronaf na região Nordeste do Brasil. Nos últimos anos, em média, 95\% dos contratos de crédito vêm sendo direcionados para o financiamento da agricultura familiar nessa região, sendo o estado da Paraíba o detentor da maior participação no total de contratos - cerca de $97 \%$. Esse comportamento também pode ser visto no estudo de Souza et al. (2011) para o período entre 1999 e 2009. Em seguida, a região Norte apresenta a segunda maior participação do Pronaf no número de contratos de crédito rural, concentrando 77,7\% dos contratos em 2013 e 67,1\% em 2017. Destaca-se nessa região o estado do Amapá.

Tal percentual é mais baixo nas regiões Sudeste, Sul e, principalmente, Centro-Oeste. Contudo, de maneira geral, esses valores confirmam uma forte importância da agricultura familiar no Brasil, visto que a participação média dos contratos do Pronaf no período analisado gira em torno de $70 \%$ do número total de contratos de crédito rural realizados em todo o país.

Em termos de volumes de recursos, a Tabela 2 expõe a participação dos recursos do Pronaf no crédito total concedido à agricultura por regiões brasileiras, de 2013 a 2017. Pode-se observar que a participação dos valores do crédito concedido pelo Pronaf não segue uma distribuição proporcional ao número de contratos de crédito, como visto na Tabela 1. No Brasil, pode ser constatado que o valor dos recursos concedidos ao financiamento do Pronaf não chega a superar $16 \%$ do total dos recursos de crédito na agricultura, com uma participação de 14,3\% em 2013, atingindo seu ápice na série em 2014, com 15\%, e apresentando uma queda crescente até 2017 , chegando a 13\%, aproximadamente.

Tabela 2. Participação percentual dos recursos do Pronaf no crédito total concedido à agropecuária por regiões brasileiras (2013-2017)

\begin{tabular}{cccccc}
\hline \multirow{2}{*}{ Região } & \multicolumn{5}{c}{ Ano } \\
\cline { 2 - 6 } & 2013 & 2014 & 2015 & 2016 & 2017 \\
\hline SUL & 19,55 & 20,09 & 18,94 & 19,53 & 20,01 \\
\hline Paraná & 13,28 & 13,68 & 13,11 & 14,08 & 14,31 \\
Rio Grande do Sul & 23,15 & 24,09 & 23,07 & 24,13 & 23,67 \\
Santa Catarina & 26,74 & 26,84 & 26,15 & 23,89 & 26,29 \\
\hline SUDESTE & 10,55 & 11,63 & 10,16 & 9,53 & 8,93 \\
\hline Minas Gerais & 13,10 & 14,61 & 12,53 & 13,30 & 11,08 \\
São Paulo & 4,39 & 5,07 & 4,75 & 3,64 & 12,04 \\
Espírito Santo & 34,09 & 34,03 & 32,12 & 36,91 & 36,49 \\
Rio de Janeiro & 31,58 & 29,81 & 28,83 & 38,60 & 34,01 \\
\hline CENTRO-OESTE & 4,20 & 4,78 & 4,95 & 4,81 & 3,84 \\
\hline Mato Grosso & 5,18 & 6,26 & 6,70 & 6,46 & 4,99 \\
Goiás & 4,11 & 4,26 & 4,33 & 4,39 & 3,67 \\
Mato Grosso do & 2,69 & 2,97 & 3,10 & 2,79 & 2,13 \\
Sul & 5,24 & 7,40 & 2,77 & 2,35 & 2,56 \\
Distrito Federal & & & & &
\end{tabular}




\begin{tabular}{cccccc}
\hline NORDESTE & 24,85 & 24,80 & 25,23 & 25,84 & 18,53 \\
\hline Bahia & 12,94 & 14,62 & 14,50 & 14,71 & 11,68 \\
Maranhão & 22,93 & 19,94 & 19,81 & 20,12 & 12,00 \\
Piauí & 23,31 & 19,06 & 20,67 & 24,14 & 15,34 \\
Ceará & 48,88 & 48,22 & 51,01 & 50,40 & 39,14 \\
Pernambuco & 47,42 & 51,57 & 49,72 & 48,77 & 34,34 \\
Alagoas & 38,06 & 50,73 & 54,31 & 46,01 & 48,58 \\
Paraíba & 43,76 & 43,95 & 52,56 & 50,06 & 48,36 \\
Sergipe & 41,46 & 37,80 & 41,16 & 40,16 & 33,79 \\
Rio Grande do & 62,56 & 58,92 & 55,34 & 56,66 & 17,61 \\
Norte & 23,92 & 24,67 & 21,92 & 23,78 & 18,88 \\
\hline NORTE & 8,38 & 8,66 & 8,20 & 8,00 & 3,92 \\
\hline Tocantins & 24,93 & 21,91 & 21,79 & 19,51 & 12,29 \\
Pará & 36,47 & 42,48 & 37,47 & 42,01 & 38,25 \\
Rondônia & 48,35 & 56,70 & 49,39 & 51,69 & 55,01 \\
Acre & 76,81 & 42,32 & 37,08 & 42,93 & 33,77 \\
Amazonas & 41,71 & 37,23 & 38,00 & 41,83 & 30,34 \\
Roraima & 41,15 & 48,05 & 41,50 & 56,04 & 32,29 \\
Amapá & 14,31 & 15,01 & 14,11 & 14,11 & 12,91 \\
\hline BRASIL & r & &
\end{tabular}

Fonte: Elaboração própria com base em dados do Anuário Estatístico do Crédito Rural do Banco Central do Brasil. Disponível em: https://www.bcb.gov.br/estabilidadefinanceira/micrrural.

De acordo com a Tabela 2 as regiões Norte, Nordeste e Sul são as que apresentam o maior direcionamento dos recursos do crédito rural direcionados para a agricultura familiar, com $20 \%$, em média, dos recursos de crédito rural concedidos pelo Pronaf. Na região Sudeste, por sua vez, cerca de $10 \%$ do crédito rural é direcionado para o Pronaf. A região que apresenta o menor direcionamento é a Centro-Oeste, justamente onde o agronegócio tem grande representatividade, caracterizando uma agricultura mais industrial.

No que se refere ao destino do crédito concedido pelo Pronaf, o financiamento é encaminhado levando em consideração as atividades exploradas pelos grupos demandantes e pela sua renda anual. Dessa maneira, torna-se um repasse de financiamento feito de acordo com as linhas de crédito específicas, assegurando maior aproximação entre a demanda e a oferta de crédito, o endividamento e a viabilidade da quitação da dívida adquirida.

Por sua vez, em conformidade com a política de desenvolvimento agropecuário e seguindo as diretrizes formuladas pelo Conselho Monetário Nacional (CMN), os recursos utilizados pelo Pronaf para os financiamentos são oriundos das mais diversas fontes. As principais fontes de recursos são o Fundo de Amparo ao Trabalhador (FAT), o os fundos constitucionais de financiamento do Nordeste (FNE), do Centro-Oeste (FCO) e do Norte (FNO), as Operações Oficiais de Crédito e os recursos obrigatórios. Os recursos do FAT, principal fonte financiadora do Pronaf, passam primeiro por um banco público federal, o qual assume os riscos e concede garantias ao FAT, para depois ocorrer o repasse para outros agentes financeiros (BRASIL, 2017). 


\section{Metodologia \\ 3.1 Base de dados}

Os dados utilizados neste estudo são oriundos da Pesquisa Nacional por Amostra de Domicílios (PNAD) do Instituto Brasileiro de Geografia e Estatística (IBGE), referentes a 2014. Para esse ano, em específico, a pesquisa fornece um questionário suplementar que inclui questões relacionadas ao acesso e à fonte de crédito para a produção rural, em que é possível identificar se o crédito foi concedido pelo Pronaf ou por outras fontes, sejam de instituições públicas ou privadas.

Para estimar o efeito do crédito sobre a produtividade e a renda agropecuária familiar, foram considerados produtores rurais beneficiários e não beneficiários do Pronaf, entrevistados na PNAD. Considerou-se, para a composição da amostra, dois dos critérios utilizados por Ely et al. (2017): i) empregadores ou trabalhadores autônomos com no máximo cinco funcionários permanentes; e ii) recebeu crédito do Pronaf ou não recebeu crédito de outros programas, isto é, foram excluídos da amostra dos não beneficiários produtores que tiveram acesso a outros tipos de crédito, uma vez que sua permanência na análise poderia subestimar o efeito do Pronaf. Também foram excluídos da amostra produtores que faziam uso de menos de um terço de hectare, que atividade principal não foi a atividade agrícola ou com renda superior ao limite que classifica o agricultor familiar. A amostra também incluiu uma pequena parcela de administradores de propriedades rurais que vivem em áreas urbanas (IBGE, 2014). Depois de eliminar valores ausentes e outliers, a amostra final consiste em 1.928 produtores rurais, dos quais 150 foram beneficiários do Pronaf.

No modelo logit, empregado no cálculo do escore de propensão para participação do programa, a variável dependente é uma variável dummy que indica a participação ou não no Pronaf. Como controle, foram empregadas no modelo as variáveis descritas a seguir.

a) Sexo: variável dummy que indica o sexo do indivíduo, assumindo o valor 1 se esse indivíduo for do sexo masculino;

b) Idade: variável que indica a idade do indivíduo em anos completos;

c) Experiência: variável calculada como a idade do indivíduo menos a idade com que começou a trabalhar, que consiste em uma proxy para sua experiência;

d) Estado civil: uma variável dummy que é igual a 1 se o indivíduo é casado;

e) Sabe ler: variável dummy que indica se o indivíduo sabe ler;

f) Rural: variável dummy que indica se o produtor reside na zona rural;

g) Proprietário: variável dummy que indica se o produtor é proprietário da terra que utiliza na produção;

h) Dummies de região: quatro variáveis dummies que representam as macrorregiões brasileiras - Nordeste (dNordeste), Sudeste(dSudeste), Sul (dSul) e Centro-Oeste (dCentroOeste), (omitindo-se a região Norte);

i) Assistência técnica: variável dummy que indica se o indivíduo recebeu assistência técnica; e

j) Internet: variável dummy que indica se o produtor tem acesso à internet. 
Já no modelo propensity score matching (PSM), o efeito médio do tratamento sobre o grupo de tratamento, isto é, o valor ATT, é obtido para duas variáveis, elencadas a seguir.

a) InRenda: logaritmo natural da renda agropecuária; e

b) InProdutividade: logaritmo natural da produtividade agropecuária.

Ambas as variáveis estão em logaritmo natural. Dessa forma, o ATT obtido indica o efeito percentual do programa sobre essas variáveis. Essa mesma abordagem foi empregada por Cruz (2018).

\subsection{Modelos econométricos}

\subsubsection{Balanceamento por entropia}

Desenvolvida por Hainmueller (2012), o balanceamento por entropia é um método multivariado e não paramétrico que busca ajustar as distribuições das amostras por meio de uma reponderação. Ou seja, atribuem-se pesos ao conjunto de observações do grupo de controle para ajustar as unidades do grupo de tratamento. O balanceamento se faz necessário por permitir uma melhor estimação dos efeitos de tratamento aplicados por meio dos métodos de pareamento.

Com isso, considera-se uma amostra com $n_{1}$ elementos referentes ao grupo dos tratados, e $n_{0}$ unidades de controle, os quais foram selecionados aleatoriamente de uma população de tamanho $N_{1}$ e $N_{0}$, respectivamente, $\left(n_{1} \leq N_{1} e n_{0} \leq N_{0}\right)$. Considera-se também $D_{i} \in\{1,0\}$ uma variável de tratamento binária, que assumirá o valor igual a 1 se a unidade i pertencer ao tratamento, e o se pertencer ao grupo de controle.

Numa matriz $\mathrm{X}$ com observações de $\mathrm{J}$ variáveis exógenas de pré-tratamento, $X_{i j}$ equivale ao valor da j-ésima covariada da unidade i, onde $X_{i}=\left[X_{i 1}, X_{i 2}, \ldots, X_{i j}\right]$ concerne ao vetor de características da unidade i e $X_{j}$ e se refere ao vetor coluna com j covariada. A densidade das covariadas nas populações de tratamento e controle são dadas por $f_{X \mid D=1}$ e $f_{X \mid D}=0$, respectivamente. $O$ resultado potencial $Y_{i}\left(D_{i}\right)$ equivale ao par de resultados para a unidade i, dadas as condições de tratado e controle. Assim, o resultado observado é dado por $Y=Y_{1} D+(1-D) Y_{0}$.

O ATT, que mostra como foi afetado o grupo que recebeu o tratamento, é dado por $\tau=E\left[Y_{1} \mid D=1\right]-E\left[Y_{0} \mid D=1\right]$, sendo a primeira esperança atribuída ao grupo-tratados, e a segunda ao contrafactual, o qual não é observado. Rosenbaum e Rubin (1983) mostraram que, assumindo seleções observáveis, $Y_{0} \perp D \mid X$, e sobreposições, $\operatorname{Pr}(D=1 \mid X=x)<1$ para todo $\mathrm{x}$ no suporte de $f_{X \mid D=1}$, o ATT é definido como:

$$
\tau=E[Y \mid D=1]-\int E[Y \mid X=x, D=0] f_{X \mid D=1}(x) d x
$$

A fim de deixar a distribuição da covariável no grupo de controle próxima à distribuição no grupo de tratamento, fez-se o balanceamento mediante a estimação 
do último termo da equação (1), de forma que o indicador de tratamento $D$ se torne mais próximo possível em relação às covariáveis.

O balanceamento por entropia por meio do processo de reponderação possibilita que todos os dados paralelos disponíveis sejam agregados no cálculo dos pesos da população de amostras não probabilísticas, permitindo que a densidade de $\mathrm{X}$ na amostra não probabilística reponderada se retrate muito de perto à da amostra de referência. Considera-se $w_{i}$ o peso do balanceamento escolhido para cada elemento de controle, encontrado pelo seguinte esquema de reponderação que visa minimizar a distância métrica de entropia:

$$
\min _{w_{i}} H(w)=\sum_{\{i \mid D=0\}} w_{i} \log \left(w_{i} / q_{i}\right)
$$

Sendo a equação (2) sujeita a restrições de equilíbrio e normalização:

$$
\begin{aligned}
& \sum_{\{i \mid D=0\}} w_{i} c_{r i}\left(X_{i}\right)=m_{r} \quad \operatorname{com} r \in\{1, \ldots, R\} \\
& \sum_{\{i \mid D=0\}} w_{i}=1
\end{aligned}
$$

$$
w_{i} \geq 0 \text { para todo i, tal que } D=0 \text {. }
$$

Onde $q_{i}=1 / n_{0}$ é um peso base e $c_{r i}\left(X_{i}\right)=m_{r}$ descreve um conjunto de $\mathrm{R}$ restrições de equilíbrio impostas para balancear as distribuições das covariadas no grupo de controle. Primeiramente, escolhe-se a covariada que será inserida na reponderação. Para cada covariada, especifica-se um conjunto de restrições de balanceamento (equação 4) a fim de equiparar os momentos das distribuições das covariadas entre os grupos de tratamento e controles reponderados.

As restrições de momentos podem ser a média (primeiro momento), a variância (segundo momento) e a assimetria (terceiro momento). Uma restrição típica do balanceamento é formulada de tal forma que $m_{r}$ contenha o momento de uma covariada específica $X_{j}$ para o grupo de tratamento, e a função de momento para o grupo de controle é especificada como $c_{r i}\left(X_{i j}\right)=X_{i j}^{r}$ ou $c_{r i}\left(X_{i j}\right)=\left(X_{i j}-\mu_{j}\right)^{r}$ com média $\mu_{j}$.

Por conseguinte, o balanceamento por entropia procura, para um conjunto de unidades, pesos $W=\left[w_{i}, \ldots, w_{n_{0}}\right]^{\prime}$, no qual minimiza a equação (3), distancia de entropia entre W e o vetor base de pesos $Q=\left[q_{i}, \ldots, q_{n_{0}}\right]^{\prime}$, sujeita as restrições de balanceamento na equação (4), restrição de normalização (equação 5).

\subsubsection{Propensity Score Matching}

Posteriormente ao balanceamento pela entropia, faz-se necessário estimar um modelo que possibilite a comparação entre indivíduos semelhantes e características observáveis. Para tanto, utilizou-se o Propensity Score Matching (PSM), metodologia desenvolvida por Rosenbaum e Rubin (1983). 
O PSM é um procedimento técnico semiparamétrico que visa constituir um grupo de controle semelhante ao grupo de tratamento por meio de determinadas características observáveis.

O pareamento requer que, ao verificar dois indivíduos, um no grupo de controle e o outro no grupo de tratamento, com as mesmas características observáveis, o único elemento que diferencia os resultados, neste trabalho, é a participação ou não no Pronaf.

Para isso, é estabelecido a seguinte probabilidade condicional de auferir um tratamento, dadas as características do pré-tratamento:

$P(X)=\operatorname{Pr}(D=1 / X)=E(D / X)$.

Em que $D=\{0,1\}$ é a exposição ou não ao tratamento; $X$ é um vetor de covariadas de características de pré-tratamento, ao qual está sob hipótese de interdependência condicional $D \perp\{Y(D=1), Y(D=0) \mid P(X)\}$.

Esse método apresenta uma solução prática para o problema da multidimensionalidade no pareamento. $O$ efeito de tratamento pode ser determinado de acordo com a equação:

$E\left(Y_{1}-Y_{0} \mid D=1, P(X)\right)=E\left(Y_{1} \mid D=1, P(X)\right)-E\left(Y_{0} \mid D=0, P(X)\right)$.

O viés associado às diferenças do nível das variáveis observadas é eliminado ajustando as diferenças entre as unidades de tratamento e controle, gerando um estimador que permite que a distribuição das características observadas (X) do grupo de controle e do grupo de tratamento seja idêntica.

Assim, o contrafactual pode ser construído a partir dos resultados do grupo de tratamento, de acordo com:

$$
E\left(Y_{0} \mid P(X), D=1\right)=E\left(Y_{0} \mid P(X), D=0\right)=E\left(Y_{0} \mid P(X)\right) .
$$

É possível corrigir o viés entre os grupos de tratamento e de controle por meio do PSM. Porém, para a confirmação dos resultados, há duas hipóteses que devem ser satisfeitas, cuja combinação Rosenbaum e Rubin (1983) definem como ignorabilidade forte.

A primeira hipótese concerne no balanceamento de características observáveis que independem do tratamento. Ou seja, os elementos devem ter a mesma distribuição de características observáveis e não observáveis, independentemente de serem tratadas ou não. Os grupos de tratamento e de controle carecem da mesma média para todas as características para determinado propensity score. Essa hipótese garante que cada indivíduo no grupo de tratamento tenha um par similar no grupo de controle, para comparação. Supõe-se que:

$$
Y(1), Y(0) D|X \Rightarrow Y(1), Y(0) D| P(X)
$$


com intervalo de $0<\mathrm{P}(X)<1$. Nesse caso, a variável de resultado irá corresponder à situação dessa pessoa na ausência do tratamento (BECKER; ICHINO, 2002).

Essa condição da independência condicional afirma que dado a um conjunto de covariáveis $X$ observáveis que não são afetadas pelo tratamento, gera resultados potenciais $\mathrm{Y}$ independentes de tratamento atribuídos a $\mathrm{D}$.

Ao se calcular o valor esperado da diferença da variável que se refere à situação de cada pessoa de receber ou não o tratamento para cada grupo de indivíduos tratados, em razão das não observações, não se pode ter conhecimento do valor da variável resultado para a situação de tratamento contrafactual da expressão a seguir:

$\tau=\mathrm{E}\left(\Delta_{i} \mid D_{i}=1\right)=\mathrm{E}\left(Y_{i}(1)-Y_{i}(0) \mid D_{i}=1\right)$.

A segunda hipótese é a suposição de suporte comum, em que se constitui na região onde o equilíbrio dos escores de propensão entre os grupos de controle e de tratamento se apresentam. Essa região de suporte comum é obtida com base no descarte daqueles casos que estiverem muito abaixo ou muito acima da média dos escores, ou seja, não são unidades comparáveis, e são grupos que não permitem inferir as conclusões propostas pela avaliação de impacto.

Para Ichino (2006), pode ser interpretado como um problema de missing data e que os métodos de pareamento são a maneira de atribuir valores aos resultados contrafactuais ( $\mathrm{Yi}(0) \mid \mathrm{Di}=1)$. Costa et al. (2016) enfatizam que esse problema pode ser resolvido aliando o propensity score ao matching. Assim, para realizar o pareamento, diferentes métodos são utilizados - pareamento por vizinho mais próximo, pareamento por alcance e pareamento Kernel -, sendo escolhido aquele que demonstrar o melhor pareamento entre o grupo de controle e o tratamento.

Dessa forma, para estimar o impacto do Pronaf sobre a renda e a produtividade dos agricultores, os pesos encontrados no balanceamento por entropia foram combinados com o método do PSM, visando melhorar o balanceamento das covariáveis e adquirir valores mais confiáveis, conforme aplicado por Watson e Elliot (2016) e Costa et al. (2016).

\section{Resultados e discussões}

Nesta seção, serão observadas as estatísticas descritivas relativas à renda e à produtividade agropecuária de beneficiários e não beneficiários do Pronaf. Após essas descrições, serão demonstrados os resultados do modelo logit usado no cálculo do escore de propensão, do balanceamento por entropia e das estimações do PSM.

\subsection{Estatística descritiva da amostra}

$\mathrm{Na}$ tabela 3 são expostas as distribuições de frequência, absolutas e relativas, de beneficiários e não beneficiários do Pronaf, de acordo com a faixa de renda agropecuária. É possível observar que a renda média de $\mathrm{R} \$$ 995,51 dos 
beneficiários é superior à renda média de $\mathrm{R} \$$ 932,16 dos não beneficiários. Pode-se observar também que, tanto no grupo dos beneficiários como no dos não beneficiários, a faixa de renda que concentra a maior parte da amostra é a dos que apresentaram rendimentos de $\mathrm{R} \$ 1$ mil a $\mathrm{R} \$ 1,5$ mil ao mês. Como o Pronaf é um programa direcionado para a agricultura familiar, estão excluídos da amostra produtores com renda estimada em mais de $\mathrm{R} \$ 20$ mil por ano. A faixa de renda com a menor concentração de produtores, para ambos os grupos, é a de renda mensal inferior ou igual a $\mathrm{R} \$ 200$.

Tabela 3. Frequências absolutas e relativas dos beneficiários e não beneficiários do Pronaf segundo faixa de renda mensal (em R\$ de 2014)

\begin{tabular}{c|cc|cc}
\hline \multirow{2}{*}{$\begin{array}{c}\text { Faixa de renda mensal } \\
\text { (R\$) }\end{array}$} & \multicolumn{2}{|c|}{ Beneficiários } & \multicolumn{2}{c}{ Não beneficiários } \\
\cline { 2 - 5 } & Absolutas & Relativas (\%) & Absolutas & Relativas (\%) \\
\hline Até 200 & 3 & 2,00 & 73 & 4,11 \\
200 a 500 & 12 & 8,00 & 257 & 14,45 \\
500 a 750 & 28 & 18,67 & 357 & 20,08 \\
750 a 1 mil & 33 & 22,00 & 296 & 16,65 \\
1 mil a 1,5 mil & 52 & 34,67 & 526 & 29,58 \\
1,5 mil a 2 mil & 22 & 14,67 & 269 & 15,13 \\
\hline Total & \multicolumn{2}{|c|}{$\mathbf{1 5 0}$} & $\mathbf{1 0 0 , 0 0}$ & \multicolumn{2}{c}{$\mathbf{1 . 7 7 8}$} & $\mathbf{1 0 0 , 0 0}$ \\
\hline Renda média & \multicolumn{2}{|c|}{ R\$95,51 932,16 }
\end{tabular}

Fonte: Elaboração própria com base em dados da PNAD (2014).

A maioria dos produtores, beneficiários e não beneficiários, se concentrou nas classes com rendimentos mais elevados. No entanto, é interessante destacar que o percentual de não beneficiários do Pronaf nas classes de rendimentos mais baixos é maior em comparação com os beneficiários, o que pode ser indício de uma influência positiva do programa sobre a renda ou que os produtores de menor renda têm maiores dificuldades em acesso ao programa. Rocha Junior et al. (2017) identificaram que uso do crédito rural do Pronaf associa-se a uma série de fatores que definem o perfil de cada produtor, pois observaram que o aumento da escolaridade e ser proprietário da terra em que trabalha aumenta a probabilidade de o indivíduo usar do crédito rural. Dessa forma, concluíram que a efetividade do Pronaf como programa de financiamento para a agricultura familiar demanda ações mais abrangentes de assistência técnica e de capacitação administrativa, uma vez que os agricultores familiares brasileiros são caracterizados como um público vulnerável financeira e socialmente.

Já a tabela 4 apresenta as distribuições de frequência, absolutas e relativas, de beneficiários e não beneficiários do Pronaf, de acordo com a faixa de produtividade agropecuária, em reais, por hectare.

Tabela 4. Frequências absolutas e relativas dos beneficiários e não beneficiários do Pronaf segundo faixa de produtividade por hectare (em $\mathrm{R} \$$ de 2014)

\begin{tabular}{c|cc|cc}
\hline \multirow{2}{*}{$\begin{array}{c}\text { Faixa de produtividade } \\
\text { agropecuária (R\$/ha) }\end{array}$} & \multicolumn{2}{|c|}{ Beneficiários } & \multicolumn{2}{c}{ Não beneficiários } \\
\cline { 2 - 5 } & Absolutas & Relativas (\%) & Absolutas & Relativas (\%) \\
\hline Até 200 & 33 & 22,00 & 455 & 25,59
\end{tabular}




\begin{tabular}{|c|c|c|c|c|}
\hline 200 a 500 & 10 & 6,67 & 210 & 11,81 \\
\hline 500 a 750 & 23 & 15,33 & 264 & 14,85 \\
\hline 750 a $1 \mathrm{mil}$ & 27 & 18,00 & 220 & 12,37 \\
\hline $1 \mathrm{mil} \mathrm{a} 1,5 \mathrm{mil}$ & 40 & 26,67 & 393 & 22,10 \\
\hline $1,5 \mathrm{mil} \mathrm{a} 2 \mathrm{mil}$ & 16 & 10,67 & 185 & 10,40 \\
\hline 2 mil ou mais & 1 & 0,67 & 51 & 2,87 \\
\hline Total & 150 & 100,00 & 1.778 & 100,00 \\
\hline Produtividade média & \multicolumn{2}{|c|}{$\mathrm{R} \$ 892,47$} & \multicolumn{2}{|c|}{$\mathrm{R} \$ 875,47$} \\
\hline
\end{tabular}

Nota-se que a classe que predomina entre os beneficiários é a dos que apresentam produtividade por hectare de $\mathrm{R} \$ 1$ mil a $\mathrm{R} \$ 1,5$ mil, diferentemente dos não beneficiários, em que a maioria dos produtores está concentrada na faixa de produtividade inferior ou igual a $\mathrm{R} \$ 200$. Entretanto, vale salientar que, para o grupo dos beneficiários, apesar de não ser a classe mais expressiva, a faixa de produtividade inferior ou igual a $\mathrm{R} \$ 200$ por hectare também apresenta um percentual elevado, indicando uma participação relevante de produtores com baixa produtividade em ambos os grupos.

No que se refere à produtividade média, o grupo dos beneficiários do Pronaf também apresentou melhor desempenho - sua produtividade média é de $R \$ 892,47$ por hectare, enquanto para os não beneficiários esse valor é de $\mathrm{R} \$ \mathbf{8 7 5 , 4 7}$. Tal resultado pode estar associado ao fato de que o acesso ao crédito possibilita a aquisição de melhores insumos, como incorporação de novas tecnologias no processo de produção. Consequentemente, isso aumenta o nível de eficiência da produção e, dessa forma, a produtividade.

\subsection{Resultados do modelo}

A seguir, apresentam-se, respectivamente, os resultados do modelo logit utilizado para calcular o escore de propensão, o ajustamento das covariáveis obtidas pelo balanceamento por entropia, bem como os efeitos do Pronaf sobre a renda e a produtividade agropecuária dos pequenos produtores rurais beneficiados, estimados por meio do método PSM.

\subsubsection{Modelo logit}

A tabela 5 apresenta os resultados do modelo logit utilizado para calcular o escore de propensão, posteriormente empregado no balanceamento por entropia. Esses resultados demonstram as variáveis que afetam a probabilidade de 0 indivíduo ser do grupo de tratamento, isto é, beneficiário da política de crédito.

Tabela 5. Resultado do modelo de regressão logit de propensão a participação no programa

\begin{tabular}{lcccc} 
Variável & Coeficiente & Erro padrão & $\mathrm{z}$ & $\mathrm{P}>\mathrm{z}$ \\
\hline Sexo & 1,3428 & 0,4725 & 2,84 & 0,004 \\
Idade & 0,0317 & 0,0348 & 0,91 & 0,362 \\
Experiência & $-0,0186$ & 0,0327 & $-0,57$ & 0,569
\end{tabular}




$\begin{array}{lcccc}\text { Casado } & -0,3609 & 0,3926 & -0,92 & 0,358 \\ \text { Internet } & 0,6156 & 0,3608 & 1,71 & 0,088 \\ \text { Sabeler } & 0,5723 & 0,2679 & 2,14 & 0,033 \\ \text { Rural } & 0,4426 & 0,3219 & 1,37 & 0,169 \\ \text { Proprietário } & 0,4554 & 0,2454 & 1,86 & 0,064 \\ \text { Assistência técnica } & 1,9520 & 0,2023 & 1,24 & 0,000 \\ \text { dNordeste } & 0,3128 & 0,2514 & 1,28 & 0,213 \\ \text { dSul } & 0,3582 & 0,2801 & 1,22 & 0,201 \\ \text { dSudeste } & 0,3598 & 0,2947 & 1,12 & 0,222 \\ \text { dCentroOeste } & 0,4652 & 0,4140 & 9,65 & 0,261 \\ \text { Constante } & -6,4656 & 0,8648 & -7,48 & 0,000\end{array}$

Fonte: Elaboração própria com base em dados da PNAD (2014).

Obs.: Log pseudolikelihood = -454,99049 (função de verossimilhança); Pseudo $R^{2}=0,1367$; LR chi2(13) = 33,18; Prob > chi2 = 0,0000; Número de observações = 1.928 .

Assim como em Alencar, Justo e Alves (2018), no presente estudo realizou-se apenas a análise do sinal dos coeficientes estatisticamente significantes, determinando se a variável apresenta influência negativa ou positiva.

Apenas os coeficientes das variáveis dummies "Sexo", "Internet", "Sabe ler", "Proprietário" e "Assistência técnica" são estatisticamente significantes. Ou seja, dessa forma, são variáveis significantes para determinar a probabilidade de o indivíduo ser beneficiário do programa. Os coeficientes das variáveis "Sexo" e "Assistência técnica" são estatisticamente significantes a 1\%; da variável "Sabe ler", a 5\%; e das variáveis "Internet" e "Proprietário", a 10\%.

Com relação às variáveis dummies "Sexo", "Internet", "Sabe ler", "Proprietário" e "Assistência técnica”, todas apresentam sinal positivo, indicando que ser do sexo masculino, ter acesso à internet, saber ler, ser proprietário da propriedade em que trabalha e ter assistência técnica são características que aumentam a probabilidade de o indivíduo ser beneficiário do Pronaf. Esses resultados estão de acordo com o que se esperava.

Com relação aos critérios que indicam a qualidade do modelo, como desejável, o valor da função de verossimilhança (log likelihood) é consideravelmente baixo, indicando que o modelo está adequado. Quanto ao Pseudo $\mathrm{R}^{2}$, está compatível com estudos de mesma natureza já realizados, tais como os de Pereira et al. (2015) e Alencar, Justo e Alves (2018). Já com base na estatística LR qui-quadrado, observa-se que o modelo é significante a $1 \%$. Ante tais critérios, conclui-se que esse modelo está adequado.

\subsubsection{Balanceamento por entropia}

Antes da comparação pelo PSM, realizou-se o balanceamento por entropia das covariáveis do estudo. Esse balanceamento tem como finalidade tornar a amostra mais homogênea e eliminar vieses de seleção, comumente incorridos na avaliação de políticas públicas.

Na tabela 6, apresenta-se o comportamento da média, da variância e da assimetria da distribuição das covariáveis da amostra de tratamento e controle (beneficiários e não beneficiários da política). 
Tabela 6. Balanceamento por entropia

\begin{tabular}{|c|c|c|c|c|c|c|}
\hline \multirow{3}{*}{ Covariáveis } & \multicolumn{6}{|c|}{ Antes do balanceamento } \\
\hline & \multicolumn{3}{|c|}{ Tratado } & \multicolumn{3}{|c|}{ Controle } \\
\hline & Média & Variância & Assimetria & Média & Variância & Assimetria \\
\hline Sexo & 0,97 & 0,03 & $-5.199,00$ & 0,88 & 0,10 & $-2.392,00$ \\
\hline Idade & 48,03 & 130,50 & 0,05 & 46,62 & 166,10 & 0,10 \\
\hline Experiência & 37,45 & 155,70 & 0,01 & 35,91 & 186,90 & 0,08 \\
\hline Casado & 0,05 & 0,05 & $3.976,00$ & 0,08 & 0,08 & $3.044,00$ \\
\hline Internet & 0,09 & 0,08 & $2.938,00$ & 0,04 & 0,04 & $4.776,00$ \\
\hline Sabe ler & 0,87 & 0,12 & $-2.157,00$ & 0,74 & 0,19 & $-1.122,00$ \\
\hline Rural & 0,92 & 0,07 & $-3.096,00$ & 0,86 & 0,12 & $-2.054,00$ \\
\hline Proprietário & 0,83 & 0,14 & $-1.789,00$ & 0,75 & 0,19 & $-1,15$ \\
\hline Assistência técnica & 0,43 & 0,25 & 0,30 & 0,08 & 0,08 & $2.991,00$ \\
\hline dNordeste & 0,31 & 0,21 & 0,84 & 0,40 & 0,24 & 0,41 \\
\hline dSul & 0,25 & 0,19 & $1.175,00$ & 0,13 & 0,11 & $2.247,00$ \\
\hline dSudeste & 0,17 & 0,14 & $1.726,00$ & 0,13 & 0,11 & $2.194,00$ \\
\hline \multirow[t]{4}{*}{ dCentroOeste } & 0,06 & 0,06 & $3.705,00$ & 0,06 & 0,05 & $3.899,00$ \\
\hline & \multicolumn{6}{|c|}{ Depois do balanceamento } \\
\hline & \multicolumn{3}{|c|}{ Tratado } & \multicolumn{3}{|c|}{ Controle } \\
\hline & Média & Variância & Assimetria & Média & Variância & Assimetria \\
\hline Sexo & 0,97 & 0,03 & $-5.199,00$ & 0,97 & 0,03 & $-5.179,00$ \\
\hline Idade & 48,03 & 130,50 & 0,05 & 47,99 & 130,40 & 0,06 \\
\hline Experiência & 37,45 & 155,70 & 0,01 & 37,42 & 155,60 & 0,02 \\
\hline Casado & 0,05 & 0,05 & $3 \cdot 976,00$ & 0,05 & 0,05 & $3 \cdot 966,00$ \\
\hline Internet & 0,09 & 0,08 & $2.938,00$ & 0,09 & 0,08 & $2.931,00$ \\
\hline Sabe ler & 0,87 & 0,12 & $-2.157,00$ & 0,87 & 0,12 & $-2.143,00$ \\
\hline Rural & 0,92 & 0,07 & $-3.096,00$ & 0,92 & 0,07 & $-3.082,00$ \\
\hline Proprietário & 0,83 & 0,14 & $-1.789,00$ & 0,83 & 0,14 & $-1.776,00$ \\
\hline Assistência técnica & 0,43 & 0,25 & 0,30 & 0,43 & 0,24 & 0,29 \\
\hline dNordeste & 0,31 & 0,21 & 0,84 & 0,31 & 0,21 & 0,83 \\
\hline dSul & 0,25 & 0,19 & $1.175,00$ & 0,25 & 0,19 & $1.165,00$ \\
\hline dSudeste & 0,17 & 0,14 & $1.726,00$ & 0,17 & 0,14 & $1.713,00$ \\
\hline dCentroOeste & 0,06 & 0,06 & $3.705,00$ & 0,06 & 0,06 & $3.697,00$ \\
\hline
\end{tabular}

Fonte: Elaboração própria com base em dados da PNAD (2014).

É possível observar a existência de diferenças entre o grupo-tratamento e o grupo-controle antes da realização do balanceamento das covariáveis. A partir da realização do procedimento, com o ajustamento das estatísticas, a média, a variância e a assimetria das covariáveis tornaram-se muito semelhantes entre o grupo-controle e o grupo-tratado, ou seja, um perfeito balanceamento e ajustamento para os três primeiros momentos da distribuição das variáveis explicativas. 


\subsubsection{Resultado do PSM}

Após a realização do balanceamento por entropia, passou-se para o cálculo do efeito médio do Pronaf sobre a renda e a produtividade agropecuária dos produtores rurais com o uso do método PSM. Utilizando as variáveis de controle, para a obtenção do ATT, os participantes do Pronaf são pareados com os não participantes, com base no escore de propensão de participação no programa. $O$ ATT consiste na diferença média da variável de resultado dos pares de tratados e controle, formados por meio do matching ou pareamento.

Existem vários métodos de pareamento pelo PSM para obtenção do ATT. Neste estudo serão calculados os ATTs com os métodos de Kernel, do vizinho mais próximo e o Radius. O método de pareamento mais adequado para a análise será o que apresentar o menor Pseudo $\mathrm{R}^{2}$.

A tabela 7 indica os valores ATTs que representam o efeito médio do Pronaf sobre a renda e a produtividade dos produtores rurais beneficiários. Tanto para obtenção do efeito sobre a renda como sobre a produtividade, o método de pareamento empregado foi o de Kernel, dado que, em ambas as estimações, este apresentou o menor Pseudo R².

Tabela 7. Efeito médio do Pronaf sobre a renda e a produtividade agropecuária

\begin{tabular}{cccc}
\hline Método & $\begin{array}{c}\text { ATT } \\
\text { (diferença) }\end{array}$ & Erro padrão & Estatísticat \\
\hline InRenda & $0,1090^{*}$ & 0,0440 & 2,48 \\
InProdutividade & $0,1516^{*}$ & 0,0588 & 2,58 \\
\hline
\end{tabular}

Fonte: Elaboração própria com base em dados da PNAD (2014).

Obs.: * significante a $1 \%$.

No que se refere ao efeito do Pronaf sobre a renda do produtor rural, o resultado da estimação foi estatisticamente significante a $1 \%$ e apresentou sinal positivo, indicando efeito positivo do programa sobre a renda. Dado que se utilizou o logaritmo natural da renda, pode-se afirmar que o programa apresenta efeito médio positivo de 10,9\% sobre a renda dos seus beneficiários em relação aos não beneficiários. Esse resultado já era esperado, uma vez que, tendo acesso ao crédito, o produtor dispõe de recursos para custeio e investimento nas atividades agropecuárias, o que tem impacto direto na sua renda.

Esse resultado diverge do que foi encontrado no estudo de Kageyama (2003). Com dados de oito estados brasileiros, ao comparar os produtores agrícolas familiares que receberam crédito do Pronaf com os que não receberam, essa autora concluiu que a presença do programa não foi associada a uma maior renda familiar, apesar de apresentar forte correlação com as variáveis tecnológicas e com a produtividade agrícola.

Quanto ao efeito do Pronaf sobre a produtividade agropecuária, o resultado foi positivo e estatisticamente significante a $1 \%$, o que confirma o efeito positivo do programa. Com base no valor ATT do logaritmo natural da produtividade, pode-se afirmar que o Pronaf tem um efeito médio positivo de 15,2\% sobre a produtividade agropecuária dos beneficiários do programa. Em outras palavras, os beneficiários 
do Pronaf apresentam em média uma produtividade 15,2\% maior em comparação aos não beneficiários, o que também já era esperado.

Santos e Braga (2013), com dados do censo agropecuário de 2006, ao mensurar os impactos do crédito rural (não apenas Pronaf) sobre a produtividade da terra e do trabalho nas regiões brasileiras, verificaram que o crédito apresentou efeito positivo apenas na região Nordeste, sem impacto sobre a produtividade dos fatores no setor agrícola nas demais regiões. Essa divergência com os resultados do presente estudo pode ser relacionada ao fato de que a análise realizada pelos autores não separa produtores familiares de não familiares.

É interessante destacar que o impacto sobre a produtividade foi maior do que o impacto sobre a própria renda, o que corrobora, em parte, Kageyama (2003), que destaca o efeito do Pronaf sobre variáveis relacionadas à tecnologia e produtividade. Sendo assim, tal resultado pode estar associado ao fato de que, com a obtenção de recursos pelo Pronaf, os produtores melhoram seu nível de eficiência, com a aquisição de insumos mais modernos, como melhores equipamentos, sementes melhoradas, entre outros.

É importante destacar que, devido a limitação amostral, este estudo considera a média para o Brasil, o que dificulta a visualização das diferentes realidades regionais, uma vez que a condição regional pode influenciar a efetividade da política em questão.

\section{Considerações finais}

Além de apresentar um panorama acerca da distribuição do número de contratos e do volume de recursos entre as grandes regiões e estados brasileiros, 0 presente estudo teve como objetivo central avaliar os efeitos do Pronaf sobre a renda e a produtividade agropecuária dos beneficiários do programa. Para isso, utilizou-se o método PSM. Esse método consiste em uma comparação, por meio de um pareamento, entre beneficiários e não beneficiários da política, de forma a considerar a probabilidade de ambos de participar da política avaliada.

As principais contribuições deste estudo, frente aos diversos trabalhos existentes que estudam os efeitos do Pronaf, consistem na utilização de um método capaz de mensurar o efeito médio direto do Pronaf sobre o nível de renda e produtividade do pequeno produtor rural combinado com o uso de uma base de dados bem consolidada, com informações recentes e pouco exploradas para analisar questões dentro da temática abordada, além fazer uma análise a nível nacional.

Dessa maneira, o presente estudo fornece novas evidências no que diz respeito a efetividade do programa diretamente sobre a renda e produtividade dos produtores rurais beneficiados.

Observando a distribuição do número de contratos e do volume de recursos, foi possível concluir que a política é bastante heterogênea entre as regiões brasileiras com relação ao crédito e ao número de contratos. Assim sendo, sugerese uma readequação e reformulação do Pronaf para atendimentos das diferentes regiões no Brasil. 
Também se verificou que indivíduos do sexo masculino, que sabem ler, são proprietários de terra, acessam a internet e contam com assistência técnica têm maior probabilidade de ser beneficiários do programa.

Como principal conclusão, a partir dos resultados do PSM, confirmou-se que o Pronaf tem relevante impacto positivo, tanto sobre a renda como sobre a produtividade agropecuária, isto é, houveram relevantes modificações positivas na renda e na produtividade agropecuária dos beneficiários do Pronaf, o que reflete a viabilidade da política implementada.

Em suma, recomenda-se ao poder público, além de uma melhor redistribuição de contratos e volume de recursos entre as regiões brasileiras, a continuidade e a ampliação do programa, no sentido de melhorar seus resultados e expandir o número de produtores beneficiados. Isso garantiria a autonomia econômica da pequena agricultura, além do contínuo desenvolvimento socioeconômico dos produtores rurais.

\section{REFERÊNCIAS}

ALENCAR, M. O. de; JUSTO, W. R.; ALVES, D. F. Os efeitos do programa "Uma Terra e Duas Águas $(\mathrm{P} 1+2)$ " sobre a qualidade de vida do pequeno produtor rural do Semiárido nordestino. Revista Econômica do Nordeste, v. 49, n. 1, p. 165-180, 2018.

ANTUNES, R. L.; CAMARA, M. R. G.; NASCIMENTO, S. P.; SEREIA, V. J.; ANHESINI, J. A. R. Programa nacional de crédito da agricultura familiar e impactos nas economias locais no estado do Paraná. Economia \& Região, v. 1, n. 1, p. 69-90, 2013.

AQUINO, J. R. de; GAZOLLA, M.; SCHNEIDER, S. Dualismo no campo e desigualdades internas na agricultura familiar brasileira. Revista de Economia e Sociologia Rural, v. 56, n. 1, p. 123-142, 2018.

ARAUJO, J. A.; VIEIRA FILHO, J. E. R. Análise dos impactos do Pronaf na agricultura do Brasil no período de 2007 a 2016. Rio de Janeiro: Ipea, 2018. (Texto para Discussão, n. 2412).

BCB - BANCO CENTRAL DO BRASIL. Disponível em: <https://www.bcb.gov.br>. Acesso em: 12 de Novembro de 2018.

BECKER, S. O.; ICHINO, A. Estimation of average treatment effects based on propensity score. The Stata Journal, v. 2, n. 4, p. 358-377, 2002.

BITTENCOURT, G. A. Abrindo a caixa preta: o financiamento da agricultura familiar no Brasil. 2003. Dissertação (Mestrado) - Instituto de Economia, Universidade Estadual de Campinas, Campinas, 2003.

BRASIL. Ministério da Agricultura, Pecuária e Abastecimento. Plano agrícola e pecuário 2017/2018. Brasília: Mapa, 2017. 
. Banco Central do Brasil. Manual de Crédito Rural (MCR). Brasília: BC, 2018. Disponível em: <https://www3.bcb.gov.br/mcr>. Acesso em: 10 nov. 2018.

. Decreto $\mathrm{n}^{\mathrm{0}}$ 1.946, de 28 de junho de 1996. Cria o Programa Nacional de Fortalecimento da Agricultura Familiar - Pronaf, e dá outras providências. Diário Oficial da União, Brasília, 28 junho 1996.

. Resolução $n^{0}$ 4.364, de 28 de agosto de 2014. Ajusta o disposto na Seção 17 (Créditos para os Beneficiários do PNCF e do PNRA), e suas remissões correlatas, do Capítulo 10 (Programa Nacional de Fortalecimento da Agricultura Familiar - Pronaf) do Manual de Crédito Rural (MCR). Diário Oficial da União, Brasília, $1^{\circ}$ set. 2014.

BRASIL. Lei ${ }^{\circ} 11.326$, de 24 de julho de 2006. Estabelece as diretrizes para a formulação da Política Nacional da Agricultura Familiar e Empreendimentos Familiares Rurais. Diário Oficial da União, Brasília, 24 julho de 2006.

CARMO, J. G.; CLEMENTE, E. C. A contribuição do Pronaf para o desenvolvimento rural: uma análise dos seus efeitos e desdobramentos para os assentados rurais nos municípios de Teodoro Sampaio e Caiuá - SP. Revista Tamoios, v. 14, n. 1, 2018.

CASTRO, C. N. de; RESENDE, G. M.; PIRES, M. J. de S. Avaliação dos impactos regionais do Programa Nacional de Agricultura Familiar (Pronaf). Rio de Janeiro: Ipea, 2014. (Texto para Discussão, n. 1974).

COSTA, E. M. et al. Impactos do Programa Bolsa Família no mercado de trabalho e na renda dos trabalhadores rurais. In: ENCONTRO NACIONAL DE ECONOMIA, 44., 2016, Foz do Iguaçu, Paraná. Anais... Foz do Iguaçu: Anpec, 2016.

CRUZ, N. B. Efeitos das ocupações não agropecuárias sobre a renda e as horas de trabalho em zonas rurais do Brasil. 2018. 72 f. Dissertação (Mestrado em Economia Rural) - Centro de Ciências Agrárias, Universidade Federal do Ceará, Fortaleza, 2018.

ELY, R. A.; PARFITT, R.; CARRARO, A.; RIBEIRO, F. G. Rural credit and the time allocation of agricultural households: The case of PRONAF in Brazil. Review of Development Economics, 2017.

GAZOLLA, M.; SCHNEIDER, S. Qual "fortalecimento" da agricultura familiar? Uma análise do PRONAF crédito de custeio e investimento no Rio Grande do Sul. Revista de Economia e Sociologia Rural, v. 51, n. 1, p. 45-68, 2013.

GUANZIROLI, C. E. Pronaf dez anos depois: resultados e perspectivas para o desenvolvimento rural. Revista de Economia e Sociologia Rural, v. 45, n. 2, p. 301$328,2007$. 
HAINMUELLER, J. Entropy balancing for causal effects: a multivariate reweighting method to produce balanced samples in observational Studies. Political Analysis, v. 20, p. 25-46, 2012.

IBGE - INSTITUTO BRASILEIRO DE GEOGRAFIA E ESTATÍSTICA. Censo agropecuário 2006. Rio de Janeiro: IBGE, 2009. 775 p.

IBGE - INSTITUTO BRASILEIRO DE GEOGRAFIA E ESTATÍ́STICA (IBGE). Pesquisa Nacional por Amostra de Domicílios (PNAD) 2014. Disponível em:

<https://www.ibge.gov.br/estatisticas/sociais/populacao/9127-pesquisa-nacional-poramostra-de-domicilios.html?=\&t=microdados>. Acesso em: 10 de Dezembro de 2018.

ICHINO, A. Methods for the evaluation of labor market policies. Bologna: University of Bologna Press; CEPR, 2006.

KAGEYAMA, A. A. Produtividade e renda na agricultura familiar: efeitos do Pronafcrédito. Agricultura em São Paulo, v. 50, n. 2, p. 1-13, 2003.

KAGEYAMA, A. A.; BERGAMASCO, S. M. P. P.; OLIVEIRA, J. T. A. de. Uma tipologia dos estabelecimentos agropecuários do Brasil a partir do censo 2006. Revista de Economia e Sociologia Rural, v. 51, n. 1, p. 105-122, jan./mar. 2013.

LANDAU, E.C.; MOURA, L.; CRUZ, R.K.; MIRANDA, L.F.S.; HIRSCH, A.; GUIMARÃES, D.P.; NERY, R.N. Mapeamento de indicadores cadastrais rurais do Brasil. In: XVII SIMPÓSIO BRASILEIRO DE SENSORIAMENTO REMOTO, 2015, João Pessoa-PB. Anais... João Pessoa: INPE, 2015. Disponível em: <http://www.dsr.inpe.br/sbsr2015/files/p0751.pdf>. Acesso em: 10 jan. 2019.

LOPES, D.; LOWERY, S.; PEROBA, T. L. C. Crédito rural no Brasil: desafios e oportunidades para a promoção da agropecuária sustentável. Revista do BNDES, v. 45, p. 155-196, 2016.

MAGALHÃES, A. M. et al. A experiência recente do Pronaf em Pernambuco: uma análise por meio de propensity score. Economia Aplicada, v. 10, n. 1, p. 57-74, 2006.

MARIONI, L. S. et al. Uma Aplicação de Regressão Quantílica para Dados em Painel do PIB e do Pronaf. Revista de Economia e Sociologia Rural, v. 54, n. 2, p. 221-242, 2016.

MATTEI, L. Políticas de apoio ao desenvolvimento da agricultura familiar no Brasil: O caso recente do PRONAF. Revista Econômica do Nordeste, v. 38, n. 1, p. 143-158, 2007.

MELO, M. M.; MARINHO, É. L.; SILVA, A. B. O impulso do crédito rural no produto do setor primário brasileiro. Revista Nexos Econômicos, v. 7, n. 1, p. 9-36, 2013. 
PEREIRA, A.F.C. et al. Impactos das rendas não-agrícolas sobre os indicadores de pobreza Foster-Greer-Thorbecke (FGT) para as famílias rurais do Estado do Ceará. Informe Gepec, v. 19, n. 2, p. 165-183, 2015.

ROCHA JUNIOR, A. B.; CASSUCE, F. C. C.; CIRINO, J. F. Determinantes do uso do crédito rural do Pronaf em 2014. Revista de Política Agrícola, v. 26, n. 2, p. 100-114, 2017.

RODRIGUES, G. M. O Pronaf na Zona da Mata Mineira: efeitos nos PIBs total e setorial dos municípios. Revista de Economia e Sociologia Rural, v. 57, n. 1, p. 29-48, 2019.

ROSENBAUM, P. R.; RUBIN, D. B. The central role of propensity score in observational studies for causal effects. Biometrika, v. 70, n. 1, p. 41-55, 1983.

SANTOS, R. B. N. dos; BRAGA, M. J. Impactos do crédito rural na produtividade da terra e do trabalho nas regiões brasileiras. Economia Aplicada, v. 17, n. 3, p. 299-324, 2013.

SCHNEIDER, S.; MATTEI, L.; CAZELLA, A. A. Histórico, caracterização e dinâmica recente do PRONAF - Programa Nacional de Fortalecimento da Agricultura Familiar. In: SCHNEIDER, S.; SILVA, M. K.; MARQUES, P. E. M. (Org.). Políticas Públicas e Participação Social no Brasil Rural. Porto Alegre: Editora UFRGS, 2004. p. 21-50.

SILVA, D. M. O. B. da et al. Pronaf: uma avaliação da distribuição regional dos contratos de crédito e seus impactos sobre o desenvolvimento rural do Nordeste brasileiro. OKARA: Geografia em debate, v. 11, n. 2, p. 376-396, 2017.

SILVA, P. S.; ALVES FILHO, E. Impactos econômicos do Pronaf em territórios rurais: Um estudo para o médio Jequitinhonha - MG. Revista Econômica do Nordeste, v. 40, n. 3, p. 481-498, 2009.

SOUZA, P. M. et al. Agricultura familiar versus agricultura não familiar: uma análise das diferenças nos financiamentos concedidos no período de 1999 a 2009. Revista Econômica do Nordeste, v. 42, n. 1, p. 105-124, 2011.

TELES, M. L. C. Impacto do Pronaf na produção agrícola dos municípios cearenses. 2007. Dissertação (Mestrado) - Universidade Federal do Ceará, Fortaleza, 2007.

VIEIRA FILHO, J. E. R.; SILVEIRA, J. M. F. J. da. Competências organizacionais, trajetória tecnológica e aprendizado local na agricultura: o paradoxo de Prebisch. Economia e Sociedade, v. 25, n. 3, p. 599-629, 2016.

WATSON, S. K.; ELLIOT, M. Entropy balancing: a maximum-entropy reweighting scheme to adjust for coverage error. Quality and Quantity, v. 50, n. 4, p. 1781-1797, July 2016. 
Jair Andrade Araújo. Doutor em Economia pelo CAEN/UFC e Professor do Programa de Pós-Graduação em Economia Rural - PPGER/UFC. E-mail: jaraujoce@gmail.com

Matheus Oliveira de Alencar. Graduado em Economia pela Universidade Regional do Cariri (URCA), Mestre em Economia Rural pela Universidade Federal do Ceará (UFC) e Doutorando em Economia Aplicada pela Universidade Federal do Rio Grande do Sul (UFRGS). E-mail: matheusalencar29@gmail.com

José Eustáquio Ribeiro Vieira Filho. Doutor em Teoria Econômica pela Universidade Estadual de Campinas (UNICAMP) e Pesquisador do Instituto de Pesquisa Econômica Aplicada (IPEA). E-mail: jose.vieira@ipea.gov.br

Como citar: ARAÚJO, Jair Andrade; ALENCAR, Matheus Oliveira de; VIEIRA FILHO, José Eustáquio Ribeiro. Crédito Rural e Agricultura Familiar no Brasil: uma avaliação do Programa Nacional de Fortalecimento da Agricultura Familiar. Redes (St. Cruz Sul, Online), Santa Cruz do Sul, v. 25, p. 2009-2034, $2020 . \quad$ ISSN 1982-6745. doi:https://doi.org/10.17058/redes.v25io.14470.

\section{CONTRIBUIÇÃO DE CADA AUTOR}

Jair Andrade Araújo:

a. fundamentação teórico-conceitual e problematização;

b. pesquisa de dados e análise estatística;

e. elaboração e redação do texto;

f. seleção das referências bibliográficas.

Matheus Oliveira de Alencar:

b. pesquisa de dados e análise estatística;

c. elaboração de figuras e tabelas;

e. elaboração e redação do texto;

f. seleção das referências bibliográficas.

José Eustáquio Ribeiro Vieira Filho:

a. fundamentação teórico-conceitual e problematização;

b. pesquisa de dados e análise estatística;

e. elaboração e redação do texto;

f. seleção das referências bibliográficas. 